\title{
Megathrusts exhumed
}

\author{
Plate boundary faults in subduction zones can generate large earthquakes and tsunamis. Recent studies have \\ revealed that these faults slip in various ways and may be influenced by many factors. Better understanding them \\ should improve hazard assessments.
}

T en years ago, on 11 March 2011, parts of north-eastern Japan were devastated by the magnitude 9 Tōhoku-Oki earthquake and ensuing landslides and tsunami. The potential for such an event in this region was generally underestimated, as exemplified by the tsunami overwhelming defences and triggering a nuclear disaster at the Fukushima Daiichi power plant ${ }^{1}$. Improved hazard assessments of large earthquakes and tsunamis may come from better understanding their most frequent source: megathrust faults, the interface between one tectonic plate overriding another in subduction zones. With this issue, we present a collection of recent articles in Nature Geoscience that provide insights on these faults.

Megathrusts are typically locked from less than ten to a few tens of kilometres depth owing to frictional resistance ${ }^{2}$. With ongoing subduction, strain energy accumulates in the locked area and is typically released by earthquakes ${ }^{3}$. Below and often above this seismogenic zone, the fault creeps steadily and silently, with a transition zone in between that may have variable behaviour ${ }^{2}$. Transition zones have been found to host episodes of a few to tens of centimetres of slip over a period of days to years that don't induce strong seismic waves, termed slow slip events (SSEs) ${ }^{4}$. These events have been identified mostly below but also above the seismogenic zone and sometimes precede or follow earthquakes on the same megathrust segment ${ }^{3,4}$.

A key consideration for megathrust hazard assessment is the propensity of a transition zone to slip rapidly in an earthquake along with the seismogenic zone. This is because earthquake magnitude is proportional to the slip area, and slip propagation to shallow depths can produce tsunamis that are disproportionately large for the earthquake size ${ }^{3}$. The sector above the seismogenic zone has commonly been assumed to not be locked ${ }^{2}$ and so unlikely to slip rapidly. Now, an Article by Lindsey et al. demonstrates that for megathrusts offshore

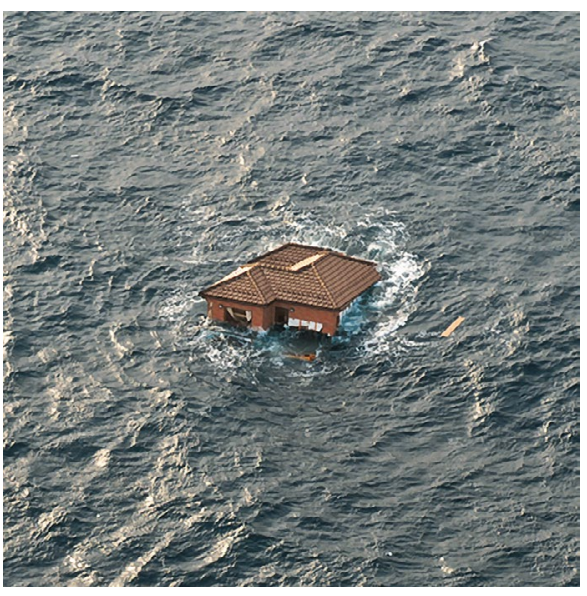

Credit: US Navy Photo / Alamy Stock Photo

of Cascadia and Japan, the area above a locked patch cannot slip substantially while the patch below is locked, and thus builds up strain energy that could be released during an earthquake. Conversely, an Article by Guo et al. considers the deeper sector beneath the seismogenic zone of the southernmost part of the Cascadia megathrust, and establishes that this transition zone has a ductile rheology, which should restrict the area that can slip rapidly and thereby the largest possible earthquake magnitude.

Another key consideration would be the relationship between earthquakes and SSEs. However, as noted in a News \& Views by Melnick, our current knowledge of SSEs is insufficient to include them in existing megathrust hazard models. An Article by Mallick et al. expands the range of known SSE behaviour by inferring an SSE on the megathrust offshore of northern Sumatra that lasted about 32 years before a magnitude 8 earthquake in 1861 . Melnick explains that the duration of this SSE is over twice as long as any previously reported, and particularly remarkable because it occurred at shallow depth (above the seismogenic zone), where SSEs found before only lasted up to a few months.
Various mechanisms have been suggested for SSEs, in part reflecting their diverse characteristics. It has been proposed that this diversity reflects the frictional behaviour of faults changing with slip rate ${ }^{5}$. Yet, an Article by Arnulf et al. shows that the frictional behaviour of a shallow part of the megathrust offshore of New Zealand's North Island must be insensitive to the slip rate, rather than dependent upon it, to generate the SSEs that it hosts.

Various factors are increasingly recognized to influence megathrust slip behaviour, particularly fluid pressure and the structure of the downgoing plate ${ }^{3}$. For example, seismicity can be affected by heterogeneity in the roughness of the downgoing plate from faulting ${ }^{6}$. Properties of the crust of the overriding plate and mantle beneath it have also been found to effect slip behaviour ${ }^{3}$ and deformation after large earthquakes ${ }^{7}$, respectively. Furthermore, an Article by Fan and Zhao suggests that heterogeneity in the mantle beneath the downgoing plate may constrain the slip location and area of the largest earthquakes. These influences could be another key consideration in megathrust hazard assessment.

The Tōhoku-Oki earthquake prompted the development of earthquake and tsunami real-time monitoring and mitigation strategies in the region ${ }^{1}$. Advances in our understanding of megathrusts since and from this event will hopefully help us to anticipate where similar measures are needed to mitigate such disasters in the future.

Published online: 7 May 2021

https://doi.org/10.1038/s41561-021-00757-6

\footnotetext{
References

1. Scott, E. Nat. Rev. Earth. Environ. 2, 231 (2021).

2. Scholz, C. H. Nature 391, 37-42 (1998)

3. Bilek, S. L. \& Lay, T. Geosphere 14, 1468-1500 (2018).

4. Schwartz, S. Y. \& Rokosky, J. M. Rev. Geophys. 45, RG3004 (2007)

5. Im, K., Saffer, D., Marone, C. \& Avouac, J.-P. Nat. Geosci. 13 705-710 (2020)

6. Kirkpatrick, J. D. et al. Nat. Geosci. 13, 369-374 (2020).

7. Luo, H. \& Wang, K. Nat. Geosci. 14, 104-109 (2021).
} 